\title{
The Development of Arylsulphatase in the Small Intestine of the Rat
}

\author{
BY S. H. DANOVITCH AND L. LASTER \\ National Institute of Arthritis and Metabolic Diseases, National Institutes of Health, \\ Bethesda, Md. 20014, U.S.A.
}

(Received 24 February 1969)

\begin{abstract}
1. Arylsulphatase activity was measured in stomach, proximal and distal third of small intestine, colon, liver and kidney of foetal and neonatal Sprague-Dawley rats and Swiss mice, with nitrocatechol sulphate as substrate. 2. The specific activity in the distal small intestine, but not in the stomach, proximal small intestine or colon, increased about fourfold between 5 and 16 days after birth in both conventional and germ-free rats. 3. No comparable increase occurred in the distal small intestine of the mouse. 4. The specific activity of acid phosphatase in the distal small intestine of the rat rose only slightly when the arylsulphatase activity increased. 5. The $\mathrm{pH}$ optimum and Michaelis constant of arylsulphatase activity of the distal small intestine were similar for 1-day-old, 9-day-old and adult rats. 6. When extracts of distal small intestine of 1-day-old and 9-day-old rats were incubated together, the arylsulphatase activities were additive.
\end{abstract}

Arylsulphatase activities, which catalyse the hydrolysis of sulphate esters of aromatic compounds, have been detected in most mammalian tissues (Roy, 1953, 1958; Dodgson, Spencer \& Thomas, 1955; Dodgson, Spencer \& Wynn, 1956). In ox liver, which has been studied most extensively, and in many other organs, there are at least three arylsulphatases, A, B and C (Roy, 1953, 1954, 1956). Available evidence suggests that arylsulphatases A and $B$ are localized in lysosomes, whereas arylsulphatase $C$ is localized in microsomes (Roy, 1960a; Sawant, Shibko, Kumta \& Tappel, 1964; Hsu \& Tappel, 1964, 1965). Arylsulphatases A and B are particularly active with NCS* as a substrate (Dodgson \& Spencer, 1957; Roy, 1960b), whereas arylsulphatase $\mathrm{C}$ is more active with NPS. The $\mathrm{pH}$ values at which optimum catalytic activity is observed are $4 \cdot 5,5 \cdot 5$ and $7 \cdot 5$ for arylsulphatases $A$, $B$ and $C$ respectively (Roy, 1953; Dodgson \& Spencer, 1957). Arylsulphatase $C$ is inhibited by cyanide and sulphite anions, whereas arylsulphatases $A$ and $B$ are inhibited by sulphate and phosphate anions (Dodgson \& Spencer, 1957; Gregory \& Robbins, 1960). During paper electrophoresis arylsulphatase $A$ moves towards the anode and arylsulphatase B towards the cathode (Roy, 1958).

Arylsulphatase activities of the mucosa of mammalian small intestine have not been characterized as well as have those of liver. Hsu \& Tappel (1964) demonstrated that activities of arylsulphatases A

* Abbreviations: NCS, nitrocatechol sulphate; 4-NC, 4-nitrocatechol; NPS, nitrophenyl sulphate; TC, sodium taurocholate. and $B$ of rat small intestine and other gastrointestinal organs are associated with the lysosomal fraction of tissue homogenates. They were unable to detect arylsulphatase $\mathrm{C}$ activity in the rat gastrointestinal tract. Studies of hog small intestine showed arylsulphatase A and B activities to be 1000 times that of arylsulphatase C (Szafran \& Szafran, 1963). The specific activities of arylsulphatase activity in mucosa and submucosa of gut tissues were approximately equal. They correlated quantitatively with the concentration of mucopolysaccharides at various locations in the rat gastrointestinal tract (Hsu \& Tappel, 1965).

We studied the development of arylsulphatase activity in the gastrointestinal tract of the rat. The specific activity increases in the distal third of the small intestine, but not in the stomach, proximal small intestine or colon, between 5 and 16 days after birth. In contrast, the specific activity of alkaline phosphatase increases in the proximal third of the small intestine, and this does not occur until about 18-20 days of age.

\section{MATERIALS AND METHODS}

Animals. The animals studied included conventional and germ-free male Sprague-Dawley rats (National Institutes of Health strain), ranging in weight from $0.5 \mathrm{~g}$. (foetuses) to $300 \mathrm{~g}$. (adult animals), and conventional Swiss mice. Foetal age was estimated from the body weight (Donaldson, 1924).

Homogenization of tissues. Fed animals were decapitated and the stomach, liver, kidneys, colon and small intestine were removed, weighed and chilled. The hollow organs were irrigated with iced $0 \cdot 25 \mathrm{M}$-sucrose solution. For 
animals less than 18 days old all layers of the wall of a hollow viseus were homogenized together, whereas for older animals mucosa was scraped away from the bowel wall with a blunt spatula and the two were homogenized individually. Tissues were homogenized at $4^{\circ}$ with a Potter-Elvehjem homogenizer fitted with a Teflon pestle (Kontes Glass Co., Vineland, N. J., U.S.A., catalogue no. K-886000, clearance $0.10-0.15 \mathrm{~mm}$., working surface area $\left.17 \cdot 1 \mathrm{~cm} .{ }^{2}\right)$, in $0.25 \mathrm{M}-$ sucrose solution or 1\% TC solution (Pfanstiehl Laboratories Inc., Waukegan, Ill., U.S.A.). The motor driving the pestle was set to rotate at $2500 \mathrm{rev} . / \mathrm{min}$. Fifty strokes of the homogenizer were applied during a 90 sec. period. Between 0.2 and $1.5 \mathrm{~g}$. of tissue was homogenized in $10-40 \mathrm{ml}$. of medium in a ratio of $1: 25(\mathrm{w} / \mathrm{v})$ to $1: 400(\mathrm{w} / \mathrm{v})$, depending on the arylsulphatase activity. The extracts prepared in $1 \%$ TC solution were centrifuged in a Spinco model L ultracentrifuge at $105000 \mathrm{~g}$ for $60 \mathrm{~min}$. at $0^{\circ}$.

Arylsulphatase assay. The term 'arylsulphatase activity' is used in this paper to designate catalytic activity determined by a modification of the method of Roy (1953) with NCS as substrate. Other investigators (Dodgson \& Spencer, 1957; Roy, 1960b) have shown that by the use of NCS and a $\mathrm{pH}$ of $5 \cdot 5$ for the assay mixture one determines the activities of arylsulphatases A and B and not of arylsulphatase C. Moreover, approx. $90 \%$ of the arylsulphatase activity of rat tissue is arylsulphatase B (Roy, 1958). Our standard incubation mixture contained: $200 \mu$ moles of sodium acetate buffer, pH5.5, $8 \mu$ moles of dipotassium NCS (Sigma Chemical Co., St Louis, Mo., U.S.A.) and $0.1 \mathrm{ml}$. of the $105000 \mathrm{~g}$ supernatant solution of the TC extract, containing $0.25-2.0 \mathrm{mg}$. of protein $/ \mathrm{ml}$. of homogenate, all in a total volume of $0.8 \mathrm{ml}$. The reaction was started by addition of enzyme and was stopped after $15 \mathrm{~min}$. of incubation at $37^{\circ}$ by addition of $1 \mathrm{ml}$. of $5 \%(\mathrm{w} / \mathrm{v})$ trichloroacetic acid. The mixture was centrifuged at $1600 \mathrm{~g}$ for $10 \mathrm{~min}$., and $1 \mathrm{ml}$. of the supernatant solution was added to $1 \mathrm{ml}$. of $5 \mathrm{M}-\mathrm{NaOH}$ solution. The resulting colour was stable for at least $60 \mathrm{~min}$. Its extinction was determined with a Beckman DU spectrophotometer at $520 \mathrm{~nm}$. With each assay two control incubation mixtures were prepared, one lacking substrate and the other lacking enzyme. All assays were performed in duplicate. A unit of activity was defined as the amount of enzyme required to catalyse the release of $1 \mu$ mole of 4-NC under the conditions of the standard assay. The method could detect activity as low as $4 \mathrm{nmoles}$ of 4-NC released/15 min.

Arylsulphatase $\mathrm{C}$ was assayed by the method of Dodgson \& Spencer (1957). NPS was purchased from the Sigma Chemical Co. Homogenates prepared in $0.25 \mathrm{~m}$-sucrose solution served as the source of enzyme. The method was sensitive enough to detect activity as low as 3 nmoles of $\boldsymbol{p}$-nitrophenol released from NPS/hr.

Alkaline and acid phosphatase assays. Tissues homogenized in sucrose solution were assayed for alkaline phosphatase activity by a modification of the method of King \& Armstrong (1934). Each incubation mixture contained:

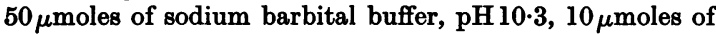
disodium phenyl phosphate (Fisher Chemical Co., Fairlawn, N.J., U.S.A.), $2 \mu \mathrm{moles}$ of $\mathrm{MgCl}_{2}$ and $50 \mu$ l. of enzyme homogenate solution, containing $0 \cdot 25-2.0 \mathrm{mg}$. of protein $/ \mathrm{ml}$., all in a total volume of $1.05 \mathrm{ml}$. The reaction was started by addition of enzyme and stopped after incubation for $15 \mathrm{~min}$. at $37^{\circ}$ by addition of $0.5 \mathrm{ml}$. of $5 \%(\mathrm{w} / \mathrm{v})$ trichloroacetic acid. After centrifugation, the released $P_{1}$ in the supernatant solution was assayed by the method of Chen, Toribara \&
Warner (1956). Control incubation mixtures similar to those used for the arylsulphatase assay were prepared, and all experiments were done in duplicate. A unit of alkaline phosphatase activity was defined as the amount of enzyme required to catalyse the release of $1 \mu$ mole of $P_{1}$ under the standard assay conditions.

The assay for acid phosphatase activity was identical with the alkaline phosphatase assay except that $40 \mu$ moles of a sodium acetate buffer, $\mathrm{pH} 4 \cdot 5$, were substituted for the sodium barbital buffer.

Protein determinations. Protein was determined by the method of Lowry, Rosebrough, Farr \& Randall (1951) with crystalline bovine albumin (Calbiochem, Los Angeles, Calif., U.S.A.) as a standard. Specific activities were expressed as units of enzyme activity/mg. of protein.

\section{RESULTS}

Properties of intestinal arylsulphatase activity. A number of properties of arylsulphatase from the distal one-third of the small intestine were determined for adult rats. Comparable results were obtained in limited studies of younger animals and of other regions of the small intestine. The rate of hydrolysis of NCS was maximal at $\mathrm{pH} 5.5$ (Fig. 1). Release of 4-NC was directly proportional to incubation time for at least $120 \mathrm{~min}$. (Fig. 2). Enzyme activity varied directly with the amount of protein in the incubation mixture, at least over the range shown in Fig. 3, and all measurements were performed so that results fell within this linear range. Heating of the tissue extract at $100^{\circ}$ for $5 \mathrm{~min}$. destroyed all arylsulphatase activity. When an amount of 4-NC equivalent to that generated during an average arylsulphatase assay was incubated with intestinal extract under conditions of the standard assay, all the 4-NC was recovered. The enzyme was essentially completely solubilized in $1 \%$ TC (Table 1, column I). The supernatant solution obtained after ultracentrifugation con-

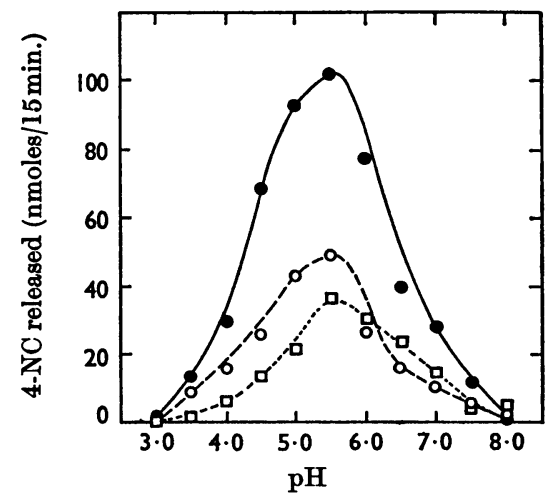

Fig. 1. Effect of pH on arylsulphatase activity in the distal small intestine of newborn $(\square), 9$-day-old $(\bullet)$ and adult $(O)$ rats. 
tained $100 \%$ of the activity of the homogenate. The supernatant solution of a homogenate prepared in distilled water contained $52 \%$ of the activity of

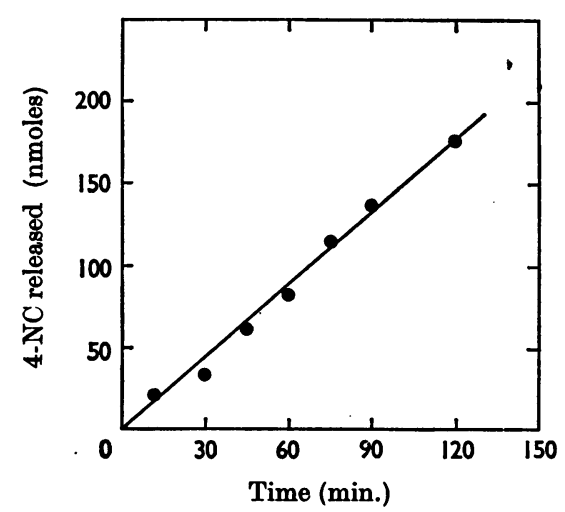

Fig. 2. Intestinal arylsulphatase activity as a function of incubation time.

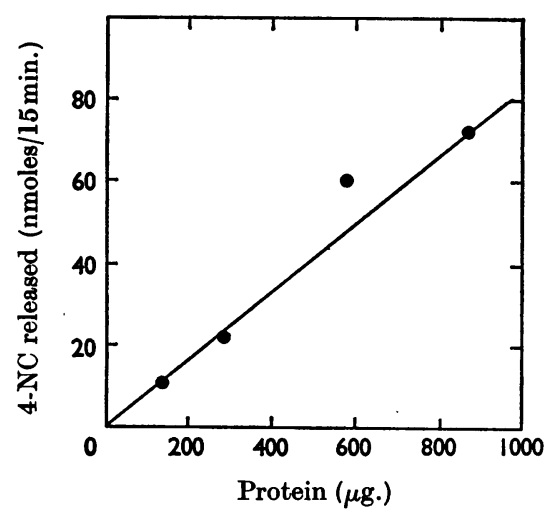

Fig. 3. Intestinal arylsulphatase activity as a function of amount of tissue protein. the homogenate (Table 1, column II). Repeated extractions of the residue with distilled water eventually resulted in complete recovery of the activity in solution. At the concentration used in the present study, TC did not inhibit arylsulphatase activity of small intestine of the adult rat.

Changes in intestinal arylsulphatase activity with age. Arylsulphatase activity in the whole wall of the entire small intestine was demonstrated in a foetal rat estimated to be 16 days old. In a 19-day-old foetus, the specific activity of the whole wall of the distal third of the small intestine was two to three times that for the 16-day-old foetus (Fig. 4). After birth, the specific activity in the proximal small intestine remained unchanged for 30 days. The specific activity in the distal third of the small intestine remained essentially unchanged during the first 3 days of life, and then began to rise until it reached a maximum at 9 days of age. Then it declined progressively until about 17 days of age, by which time it had fallen to values comparable with those seen in the newborn animal. We determined that this rise in specific activity was due to an increase in enzyme activity and not to a fall in protein concentration in the intestine. During the neonatal period the specific activity of arylsulphatase in liver and kidney approximately doubled, but the rise appeared to be progressive and the pattern of development differed from that of the distal third of the small intestine (Fig. 5). The specific activity in stomach and colon did not change significantly $(P>0 \cdot 1)$.

To determine whether the intestinal bacterial flora plays a role in stimulating the rise in arylsulphatase activity in the distal small intestine, we studied germ-free animals (Fig. 6). The same pattern of development as that seen in conventional animals was observed in germ-free animals. The developmental pattern that occurred in the rat was not seen in the Swiss mouse (Fig. 7).

\section{Table 1. Extraction of arylsulphatase activity from intestinal mucosa}

Arylsulphatase activity was determined in the distal third of the small intestine, homogenized in the media shown below. The $105000 \mathrm{~g}$ residue was resuspended in a volume equivalent to that of the original homogenate. Although results of single experiments are listed in the table, comparable distributions of activity were observed when experiments were repeated as indicated in the bottom row.

Arylsulphatase activity

( $\mu$ moles of 4-NC released/15 min.)

\begin{tabular}{|c|c|c|c|c|c|c|c|}
\hline Homogenizing medium & $\cdots$ & \multicolumn{2}{|c|}{$\underset{1 \% \mathrm{TC}}{\mathrm{I}}$} & \multirow{2}{*}{$\begin{array}{c}\text { II } \\
\text { Distilled water } \\
\text { Adult }\end{array}$} & \multicolumn{3}{|c|}{$\underset{\text { III }}{0.25 \mathrm{M}-\text { Sucrose }}$} \\
\hline Age of animal & $\cdots$ & 9 days & Adult & & 1 day & 9 days & Adult \\
\hline Homogenate (a) & & 0.274 & 0.045 & 0.052 & 0.047 & $0 \cdot 360$ & 0.057 \\
\hline $105000 \mathrm{~g}$ supernatant $(b)$ & & $0 \cdot 270$ & 0.049 & $0 \cdot 027$ & 0.008 & $0 \cdot 213$ & 0.007 \\
\hline $105000 g$ residue $(c)$ & & 0.008 & 0.002 & $0 \cdot 026$ & 0.041 & $0 \cdot 140$ & 0.047 \\
\hline Ratio $(b) /(a)$ & & 0.99 & $1 \cdot 04$ & $0 \cdot 52$ & $0 \cdot 17$ & 0.59 & $0 \cdot 12$ \\
\hline No. of additional studies & & 0 & 1 & 1 & 7 & 7 & 3 \\
\hline
\end{tabular}



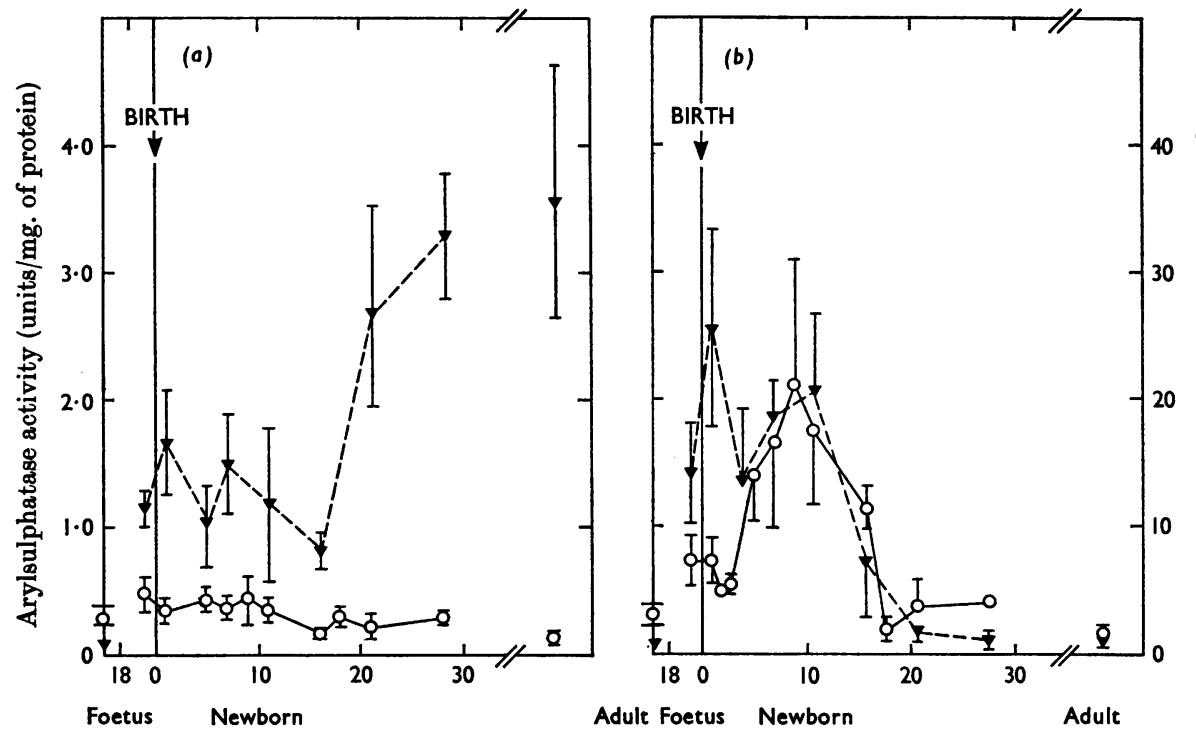

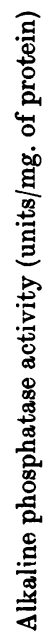

Age (days)

Fig. 4. Foetal and neonatal development of arylsulphatase $(O)$ and alkaline phosphatase $(\nabla)$ activities in proximal $(a)$ and distal $(b)$ small intestine of the rat. The mean values $( \pm 1$ s.D.) for determinations in four to 12 animals are shown. Since it was not possible to separate proximal from distal small intestine in 16-day-old foetuses, the enzyme activities were measured in extracts of the entire small intestine for animals at this stage of development. The points corresponding to these animals were included in panels $(a)$ and $(b)$ but were not joined to the remaining points because the latter represent studies in which proximal and distal intestine were assayed separately.

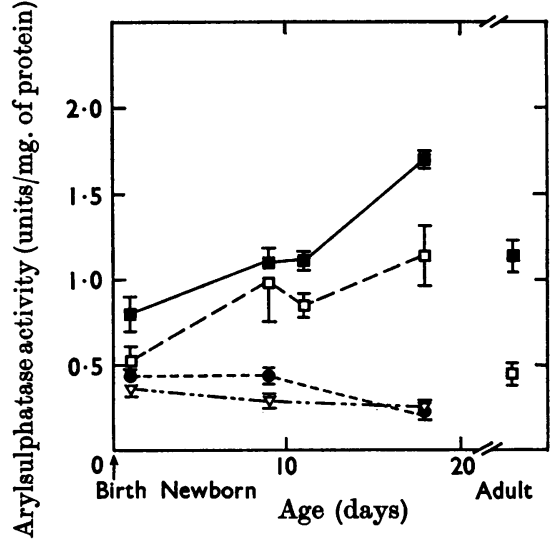

Fig. 5. Neonatal development of arylsulphatase activity in the stomach $(\nabla)$, colon $(\bullet)$, liver $(\square)$ and kidney $(\square)$. Each point represents the mean $( \pm 1$ s.D. $)$ value determined for four rats.

Properties of arylsulphatase activity of the distal small intestine of the 9-day-old rat. Additional studies were done to determine whether the high arylsulphatase activity in the distal third of the

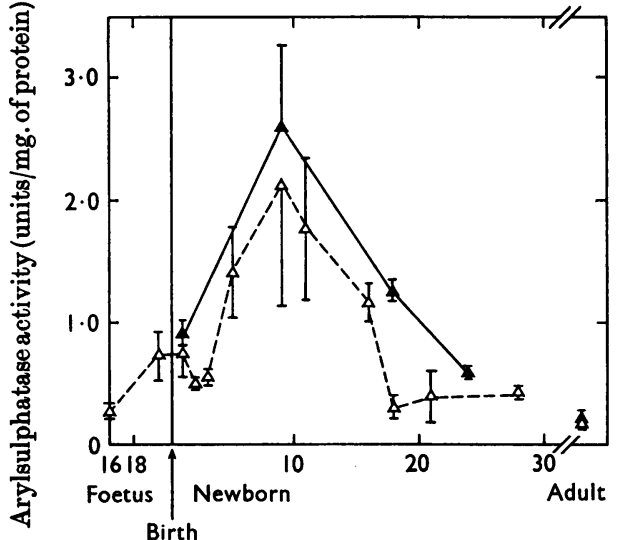

Age (days)

Fig. 6. Development of arylsulphatase activity in the distal small intestine of conventional $(\Delta)$ and germ-free $(\Delta)$ rats. Each point represents the mean ( \pm ls.D.) value determined for four to 12 animals. There are no significant differences between the two sets of results $(P>0 \cdot 1)$.

small intestine of the 9-day-old rat differed from that present in the distal small intestine of either the 1-day-old or adult rat. The maximum rate of 


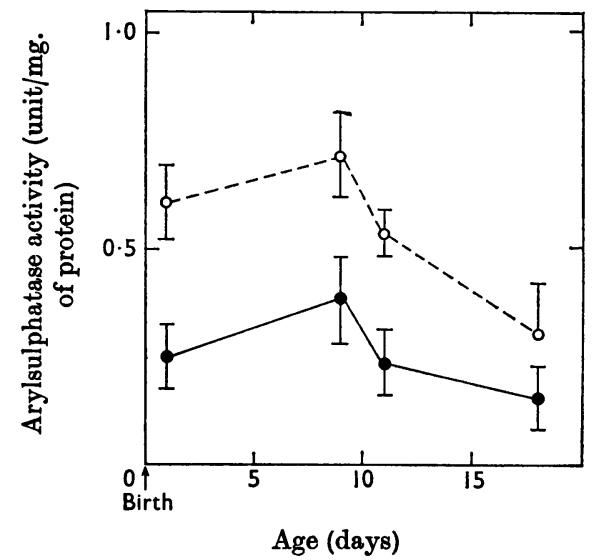

Fig. 7. Development of arylsulphatase activity in proximal $(\bullet)$ and distal (O) small intestine of the Swiss mouse. Each point represents the mean ( \pm l s.D.) value determined for four mice.

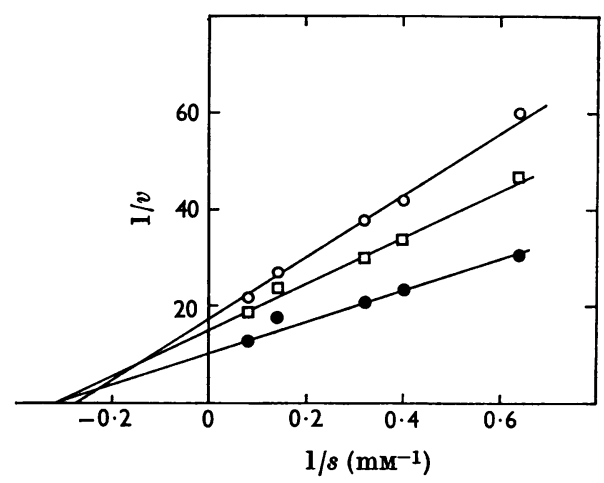

Fig. 8. Reaction rate for arylsulphatase activity in the distal small intestine of the newborn (๑), 9-day-old $(0)$ and adult $(\square)$ rats plotted by the procedure of Lineweaver \& Burk (1934) as a function of substrate concentration. The respective kinetic constants are: $K_{m} 3 \cdot 3,3 \cdot 7$ and $3 \cdot 3 \mathrm{~mm}$; $V_{\max } 0 \cdot 1,0 \cdot 06$ and $0 \cdot 07$ unit. For each age-group comparable results were obtained with three additional animals. $v$, Reaction velocity in enzyme units; $s$, substrate concentration.

hydrolysis was observed at $\mathrm{pH} 5 \cdot 5$ for each of these ages (Fig. 1). The Michaelis constants were also similar for each age (Fig. 8). The fraction of intestinal arylsulphatase activity recovered in the soluble supernatant solution after homogenization of the tissue in $0.25 \mathrm{M}$-sucrose solution was significantly greater $(P<0 \cdot 01)$ with the 9 -day-old animal than with the 1-day-old or adult animal (Table 1, column III). Despite earlier evidence, derived from cytochemical (Goldfischer, 1965) and other studies (Hsu \& Tappel, 1964, 1965), to show that in the mucosa of the small intestine of the adult rat the arylsulphatase activity is associated primarily with lysosomes, the last observation may indicate that in the 9-day-old rat either a significant fraction of the intestinal arylsulphatase activity is not associated with lysosomes, or that the intestinal lysosomes release their arylsulphatase activity more readily.

When 0.043 unit of arylsulphatase activity from the distal small intestine of a 1-day-old animal was incubated together with 0.112 unit of arylsulphatase activity from the intestine of the 9-day-old animal, the observed activity, 0.163 unit, was within $5 \%$ of the predicted activity, 0.155 unit. Thus it is unlikely that a dissociable inhibitor of arylsulphatase activity was present in the intestinal extract from the 1-day-old rat or that a dissociable stimulator was present in the intestinal extract from the 9-dayold rat.

Anatomical localization of arylsulphatase activity. The specific activity of arylsulphatase in the mucosa of the distal third of the adult rat small intestine was the same as that of the remaining submucosa and muscle layers (Table 2). Because of the small size of the intestine of perinatal rats, separation of the mucosa was difficult. Attempts to achieve such a separation in 9-day-old rats are described in the legend to Table 2. The results suggest that the mucosa and remaining small bowel wall had comparable activity. Thus the rise in arylsulphatase activity in the distal small intestine at 9 days probably occurs in both the mucosa and remaining layers.

To exclude the possibility that intraluminal material contributes to the total arylsulphatase activity of a segment of the gut, we assayed the contents of the stomach and small and large intestine of a suckling rat and found no significant arylsulphatase activity. In addition, we detected no activity in the faeces of adult animals.

We also determined whether arylsulphatase activity was secreted into the lumen by the mucosa. An everted gut sac was fashioned (Wilson \& Wiseman, 1954) from the distal third of the small intestine of an adult rat. It was incubated in KrebsRinger bicarbonate buffer, pH 7.4 (Umbreit, Burris $\&$ Stauffer, 1957), at $37^{\circ}$ in an atmosphere of $\mathrm{O}_{2}+$ $\mathrm{CO}_{2}$ (95:5), and the fluid bathing the mucosa was sampled at $0,15,30,45$ and $60 \mathrm{~min}$. after the start of the incubation. No arylsulphatase activity was found, whereas some alkaline phosphatase activity was detected in the $45 \mathrm{~min}$. and $60 \mathrm{~min}$. samples. The mucosa of the gut sac was then scraped away and its arylsulphatase specific activity was found to be normal. Thus this experiment provided no evidence that arylsulphatase activity is secreted by the mucosa of the distal small intestine of the rat.

Assessment of other enzyme activities. Acid phos. phatase activity in the distal third of the small 
Table 2. Arylsulphatase activity in intestinal mucosa compared with activity in remaining bowel wall

It was not feasible with 9-day-old rats simply to scrape the mucosa of the small intestine away from the remaining bowel wall, so the distal third of the intestine was removed intact, a fine polyethylene catheter was inserted into the lumen, the segment was irrigated with $0.25 \mathrm{M}$-sucrose then passed through the entire segment to scrape off some mucosa. The mucosal scrapings and the remaining bowel wall were homogenized and they and the perfusate were assayed for arylsulphatase activity. In experiments with adult rats the intestinal mucosa and remaining bowel wall were separated in the usual manner. Four 9-day-old and three adult rats were studied and a representative set of results for each age is presented below.

Arylsulphatase activity ( $\mu$ moles of 4-NC released) $15 \mathrm{~min} . / \mathrm{mg}$. of protein)

Mucosal scrapings

$\begin{array}{cc}\text { 9-day-old rat } & \text { Adult rat } \\ 1.74 & 0.15 \\ 1.40 & 0.16 \\ 0.36 & \end{array}$

Perfusate solution and the perfusate was collected. The catheter was

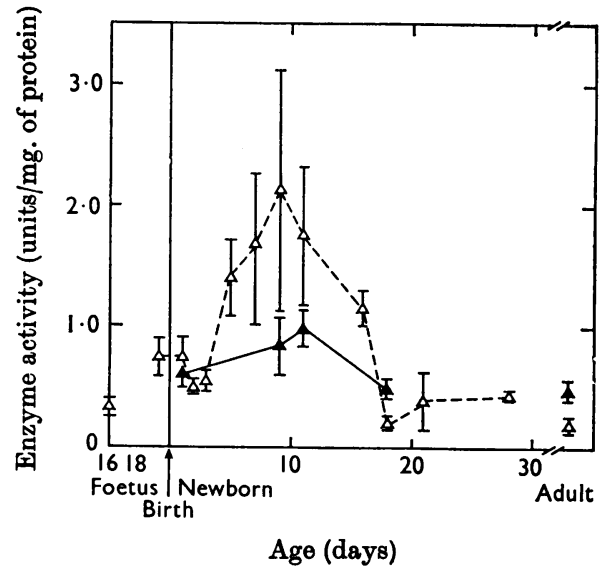

Fig. 9. Development of arylsulphatase $(\Delta)$ and acid phosphatase $(\Delta)$ activities in the distal small intestine of the rat. Each point represents the mean $( \pm$ l s.D.) value determined for four to 12 rats. The increase in arylsulphatase activity to a peak value was statistically significant $(P<0 \cdot 01)$. For acid phosphatase the significance of the difference between the peak value and that observed for day 1 is $0.05>P>0.02$. The point corresponding to the 16-day-old foetuses was not joined to the remaining points for the reasons discussed in the legend to Fig. 4.

intestine of the rat rose and fell at approximately the same period of development as arylsulphatase (Fig. 9). However, acid phosphatase activity increased by only about $50 \%$ whereas the arylsulphatase activity increased fourfold. The value for intestinal acid phosphatase specific activity differed significantly $(0.05>P>0.02)$ from that of the newborn or adult animal at 11 days of age but not at 9 days.

Alkaline phosphatase activity of the proximal small intestine differed considerably from arylsulphatase in its developmental pattern (Fig. 4a). In the proximal small intestine arylsulphatase activity remained relatively unchanged, whereas alkaline phosphatase activity increased at least threefold at the time of weaning. In the distal small intestine (Fig. 4b) alkaline phosphatase was at peak activity at birth and then gradually declined to reach adult values at the time of weaning.

No arylsulphatase $\mathrm{C}$ activity was detected in homogenates of mucosa from the small intestine of rats of various ages.

Administration of hormones. Arylsulphatase activity in the proximal and distal thirds of the small intestine was influenced by neither the subcutaneous administration of single doses of $0.1 \mathrm{mg}$. of hydrocortisone hemisuccinate or of hydrocortisone acetate/g. body wt. given at birth, at 9 days or at 21 days of age, nor the administration of $0.1 \mathrm{mg}$. of $17 \beta$-oestadiol/day during the first 3 days of life. The subcutaneous administration of $50 \mu \mathrm{g}$. of thyroid hormone/day for the first 4 days of life resulted in a slight decrease (not statistically significant) in intestinal arylsulphatase activity. In each case activity was determined at $24 \mathrm{hr}$. and $48 \mathrm{hr}$. after the administration of the last dose of the hormone.

\section{DISCUSSION}

Abundant evidence has been presented to show that in many mammalian tissues a number of acid hydrolase activities, including acid phosphatase, arylsulphatase, $\beta$-glucuronidase and $\beta$-galactosidase, are associated primarily with lysosomes (de Duve \& Wattiaux, 1966). The association of these enzymes with lysosomes has also been demonstrated for the mucosa of the adult rat small intestine (Hsu \& Tappel, 1964). In the present study we observed an increase of about $50 \%$ in acid phosphatase activity and a three- to four-fold increase in arylsulphatase activity in the distal small intestine of the rat at about 9 days after birth. Others have observed that between 5 and 15 days after birth in the distal small intestine of the rat there is a threeto four-fold increase in the activity of $\beta$-glucuronidase (Heringová, Jirsová \& Koldovský, 1965) and of $\beta$-galactosidase (Koldovský et al. 1966). By 20 days of age the specific activity of each of the four enzymes falls to adult values. These findings suggest that there may be a general, transient, increase in 
the activity of lysosomal acid hydrolases in the rat distal small intestine during the neonatal period. The pattern of change in the distal small intestine differs from that observed in the remainder of the gastrointestinal tract and in other organs such as liver and kidney (Figs. 4 and 5). The concomitant increase in the specific activity of four lysosomal enzymes may reflect an increase in the concentration of lysosomes in the distal small intestine. However, the discrepancy between the magnitude of the rise in acid phosphatase activity and that of the other three activities suggests that this may not be the entire explanation. A variation in the enzyme complement of individual lysosomes (Hugon \& Borgers, 1967) could also account for these observations.

The mechanism responsible for the neonatal increase in intestinal arylsulphatase activity was not delineated. The arylsulphatase activity in the distal small intestine of the 9 -day-old rat had values for $\mathrm{pH}$ optimum and $K_{m}$ comparable with those of the 1-day-old and adult rat. We found no evidence for the appearance of a dissociable stimulator or the disappearance of a dissociable inhibitor of arylsulphatase activity. Although Moog \& Thomas (1955) found that corticosteroids play a role in the development of intestinal alkaline phosphatase activity, under the conditions of the present study we found no evidence to implicate hydrocortisone, $17 \beta$-oestradiol or thyroid hormone in the development of either arylsulphatase or acid phosphatase activity.

The localization of the rise in intestinal arylsulphatase activity to the terminal ileum leads one to consider other metabolic processes in this region of the gut. The terminal ileum shares several functions with other areas of the small intestine, including the synthesis of peptidases (Noack et al. 1966; Hsu \& Tarver, 1967) and the transport of amino acids (Field, Schultz \& Curran, 1967), ions and water (Schultz \& Curran, 1968). We are unaware of any studies delineating the neonatal development of these transport functions in rat intestine. The patterns of development of several intestinal dipeptidase, tripeptidase and aminopeptidase activities have been studied (Heringová et al. 1966; Lindberg \& Christen, 1966) and they differ from those of arylsulphatase and acid phosphatase activities.

In addition to general functions shared with other parts of the small intestine, the terminal ileum performs at least two specific functions, the reabsorption of bile salts and the absorption of vitamin $B_{12}$. We found no information on the development of the transport system for bile salts. At birth, the absorption of vitamin $B_{12}$ by the ileum occurs independently of intrinsic factor. This independent absorption decreases sharply during the first 4 days of life, and intrinsic-factor-mediated vitamin $\mathbf{B}_{12}$ absorption increases dramatically starting at about day 4 of life (Wilson, 1966).

One might have greater insight into the role of the neonatal increase in arylsulphatase if one knew the function of the enzyme; even its main substrate in vivo is as yet unidentified. Hydrolysis of [35S]NCS in the rat does occur in vivo and in the perfused liver (Flynn, Dodgson, Powell \& Rose, 1967). Other sulphate esters are also hydrolysed in vivo (Davis et al. 1950; Dodgson \& Tudball, 1960), but not under catalytic regulation of arylsulphatases of the type examined in the present study (Burstein, 1967; French \& Warren, 1967). A deficiency of arylsulphatase activity (measured with NCS as the substrate) has been demonstrated in patients with metachromatic leucodystrophy (Austin et al. 1964; Austin, Armstrong \& Shearer, 1965). This deficiency is thought to be responsible for the accumulation of cerebroside sulphate in these patients. Whether this sulphate ester is the only or predominant substrate for arylsulphatase in mammalian tissues has not yet been determined.

\section{REFERENCES}

Austin, J., Armstrong, D. \& Shearer, L. (1965). Arch. Neurol. 13, 593.

Austin, J., McAfee, D., Armstrong, D., O'Rourke, M., Shearer, L. \& Bachhawat, B. (1964). Trans. Amer. neurol. Ass. 89, 147.

Burstein, S. (1967). Biochim. biophys. Acta, 146, 529.

Chen, P. S., Toribara, T. Y. \& Warner, H. (1956). Analyt. Chem. 28, 1756.

Davis, M. E., Kelsey, F. E., Fugo, N. W., Loucks, J. E., Horner, E. N. \& Voskuil, P. (1950). Proc. Soc. exp. Biol., N.Y., 74, 501.

de Duve, C. \& Wattiaux, R. (1966). Annu. Rev. Physiol. 28, 435.

Dodgson, K. S. \& Spencer, B. (1957). Meth. biochem. Anal. 4, 211.

Dodgson, K. S., Spencer, B. \& Thomas, T. (1955). Biochem. J. 59, 29.

Dodgson, K. S., Spencer, B. \& Wynn, C. H. (1956). Biochem. $J .62,500$.

Dodgson, K. S. \& Tudball, N. (1960). Biochem. J. 74, 154.

Donaldson, H. H. (1924). The Rat, Data and Reference Tables, p. 173. Philadelphia: The Wistar Institute of Anatomy and Biology.

Field, M., Schultz, S. G. \& Curran, P. F. (1967). Biochim. biophys. Acta, 135, 236.

Flynn, T. G., Dodgson, K. S., Powell, G. M. \& Rose, F. A. (1967). Biochem.J. 105, 1003.

French, A. P. \& Warren, J. C. (1967). Biochem. J. 105, 233. Goldfischer, S. (1965). J. Histochem. Cytochem. 13, 520.

Gregory, J. D. \& Robbins, P. W. (1960). Annu. Rev. Biochem. 29, 347.

Heringová, A., Jirsová, V. \& Koldovský, O. (1965). Canad. J. Biochem. 43, 172.

Heringová, A., Koldovský, O., Jirsová, V., Uher, J., Noack, T., Friedrich, M. \& Schenk, G. (1966). Gastroenterology, $51,1023$. 
Hsu, L. \& Tappel, A. L. (1964). J. Cell Biol. 23, 233.

Hsu, L. \& Tappel, A. L. (1965). Biochim. biophys. Acta, 101, 83.

Hsu, L. \& Tarver, H. (1967). Gastroenterology, 53, 76.

Hugon, J. \& Borgers, M. (1967). J. Cell Biol. 33, 212.

King, E. J. \& Armstrong, A. R. (1934). Canad. med. Ass. J. 31, 376.

Koldovský, O., Heringová, A., Hosková, J., Jirsová, V., Noack, R., Friedrich, M. \& Schenk, G. (1966). Biol. neonat. $9,33$.

Lindberg, T. \& Christen, O. (1966). Acta physiol. scand. $69,141$.

Lineweaver, H. \& Burk, D. (1934). J. Amer. chem. Soc. 56, 658.

Lowry, O. H., Rosebrough, N. J., Farr, A. L. \& Randall, R. J. (1951). J. biol. Chem. 198, 265.

Moog, F. \& Thomas, R. (1955). Endocrinology, 56, 187.

Noack, R., Koldovský, O., Friedrich, M., Heringová, A., Jirsová, V. \& Schenk, G. (1966). Biochem. J. 100, 775.
Roy, A. B. (1953). Biochem. J. 53, 12.

Roy, A. B. (1954). Biochem.J. 57, 465.

Roy, A. B. (1956). Biochem. J. 64, 651.

Roy, A. B. (1958). Biochem. J. 68, 519.

Roy, A. B. (1960a). Biochem.J. 77, 380.

Roy, A. B. (1960b). Advanc. Enzymol. 22, 205.

Sawant, P. L., Shibko, S., Kumta, U. S. \& Tappel, A. L. (1964). Biochim. biophys. Acta, 85, 82.

Schultz, S. G. \& Curran, P. F. (1968). In Handbook of Physiology, section 6, vol. 3, p. 1245. Ed. by Code, C. F. Washington: American Physiological Society.

Szafran, H. \& Szafran, Z. (1963). Acta biochim. pol. 11, 227.

Umbreit, W. W., Burris, R. H. \& Stauffer, J. F. (1957). Manometric Techniques, 3rd ed., p. 149. Minneapolis: Burgess Publishing Co.

Wilson, T. H. (1966). Biol. neonat. 9, 62.

Wilson, T. H. \& Wiseman, G. (1954). J. Physiol. 123, 116. 